\title{
Reducing bird numbers at New Zealand airports using a unique endophyte product
}

\author{
C.G.L. Pennell ${ }^{1}$, M.P. Rolston ${ }^{1,2}$, C. Van Koten ${ }^{3}$, D.E. Hume ${ }^{4}$ and S.D. Card ${ }^{4}$ \\ ${ }^{1}$ Forage Science, AgResearch Limited, Lincoln Research Centre, Private Bag 4749, Christchurch \\ 8140, New Zealand \\ ${ }^{2}$ The Foundation for Arable Research, PO Box 23133, Templeton, Christchurch 8445, New Zealand \\ ${ }^{3}$ Bioinformatics, Maths and Statistics, AgResearch Limited, Lincoln Research Centre, Private Bag \\ 4749, Christchurch 8140, New Zealand \\ ${ }^{4}$ Forage Science, AgResearch Limited, Grasslands Research Centre, Private Bag 11008, Palmerston \\ North 4442, New Zealand \\ Corresponding author: stuart.card@agresearch.co.nz
}

\begin{abstract}
Birds are a major issue for airport authorities worldwide creating hazards to operating aircraft. The effect of a species of grass, Schedonorus arundinaceus, colonised by a unique strain of the mutualistic fungal endophyte Epichloé coenophiala on bird abundance was examined during a series of trials at two New Zealand airports between 2007 and 2012. Fewer birds were observed on S. arundinaceus cv. Jackal AR601 plots compared with the original uncultivated ground cover for many months of the year across many years of trials. This corresponds with data collected by airport authorities on the number of bird strikes experienced by these airports before and after the introduction and establishment of S. arundinaceus cv. Jackal AR601. This plant-fungal association was later developed into the product known as Avanex.
\end{abstract}

Keywords Avanex, Epichloé, Schedonorus arundinaceus, tall fescue.

\section{INTRODUCTION}

Birds and other forms of wildlife are a major issue for airport authorities worldwide as they can create hazards to operating aircraft. Wildlife 'strikes', the majority caused by birds, can cause damage to operating aircraft and in severe cases lead to a loss of human life. Over a 22-year period from 1990, there was nearly a 6-fold increase in the number of documented bird strikes in the USA with 10,343 incidents recorded in 2012 (Federal Aviation Administration 2012). These collisions cost the USA civilian aviation industry up to US $\$ 957$ million annually in direct and other monetary losses (Dolbeer et al. 2011) and a conservative estimate of US $\$ 1.2$ billion per annum globally (Allan 2002). The increase in bird strike incidents is believed to be associated with a number of factors including a rise in passenger aircraft numbers, increasing aircraft flight routes, increasing urban sprawl, changes to land use surrounding many airports and the introduction of much quieter aircraft engines. In response, many airport authorities have prepared a proactive wildlife hazard management plan and employ resident wildlife officers in order to maintain a safe operating airport (Cleary \& Dolbeer 2005). 
The majority of bird strikes occur during the take-off or landing phase of the aircraft within the vicinity of the airport (Cleary et al. 2005). Therefore any management practice that can reduce the number of bird visits to an airport site and the surrounding vicinity is critical, not only to reduce airport wildlife management costs and damage to aircraft, but also to preserve human life. Airport management practices aimed at reducing birds in problematic areas have so far relied on various deterrents, many designed to frighten birds away from a particular area. These include distress calls, balloons, dogs, gas guns, lasers and lights (Godin 1994; Blackwell \& FernandezJuricic 2013). In many cases these solutions are only temporary (Baxter \& Allan 2008), however. Habitat modification is seen as the most effective long-term solution to reducing wildlife problems (Blackwell et al. 2009; DeVault et al. 2011). Many airfields contain large flat areas of vegetative ground cover alongside their runways. These often consist of mixtures of grass, legume and herb species, many of which produce abundant seed. Birds are attracted to the flat and open areas of airports that also provide sources of water and food (in the form of herbage, seeds and insects) (Solman 1981). There has been much debate around which plant species to use as ground cover on airport sites with no international consensus reached to date, with some authors suggesting other types of land cover should be explored such as agricultural crops (for food or biofuels) and solar power systems (Blackwell et al. 2009; DeVault et al. 2013).

Asexual fungal endophytes of the genus Epichloé infect a number of cool-season grasses in the family Poaceae (Leuchtmann et al. 2014). These endophytes form mutualistic symbiotic associations with their host grasses and produce a number of secondary metabolites (including alkaloids) that confer protection from herbivory (Johnson et al. 2013). Associated with this phenomenon, many of these grass-endophyte associations also induce avoidance behaviour in a number of mammals and birds (Coley et al. 1995; Conover \& Messmer 1996a; Durham \& Tannenbaum 1998; Pennell \& Rolston 2003;
Panaccione et al. 2006), with the metabolite ergovaline particularly implicated in this response (Pennell \& Rolston 2003). The traits associated with these endophyte-infected grasses therefore make them attractive from a wildlife management perspective (Washburn et al. 2007). AgResearch has a large collection of characterised Epichloé strains for research and development purposes (Johnson et al.2013). These strains were originally isolated from grasses collected from around the world to benefit New Zealand agriculture, particularly for deterring major pasture pests such as Argentine stem weevil (Listronotus bonariensis), pasture mealybug (Balanococcus poea) and African black beetle (Heteronychus arator) (Pennell et al. 2005). After determination of their secondary metabolite profiles, many of these endophyte strains were deemed unsuitable for pastoral use, specifically due to their high production of ergovaline, a powerful animal toxin (Johnson et al. 2013). Coupled with their capability to produce loline alkaloids, potent insecticidal and insect deterrent compounds, selected endophyte strains were deemed suitable from a wildlife deterrent perspective (Pennell et al. 2010; Finch et al. 2016; Pennell et al. 2016; Pennell et al. 2017). Consequently, an endophytegrass product was developed in New Zealand as a wildlife deterrent. Specifically, two lines of tall fescue (Schedonorus arundinaceus, syn. Festuca arundinacea), cultivar 'Jackal', were each colonised by a unique strain of the mutualistic fungal endophyte Epichloé coenophiala (Leuchtmann et al. 2014). One line was infected with strain AR601 and the other with AR604 (Pennell et al. 2010). The endophyte strain coded AR601 was later developed into a wildlife deterrent product. This product has been commercialised over the last few years (Finch et al. 2016; Pennell et al. 2016; Pennell et al. 2017) and is now available under the registered trademark of Avanex ${ }^{\circledR}$ Unique Endophyte Technology (PGG Wrightson Seeds Ltd, Christchurch, New Zealand).

The objective of this paper was to demonstrate the effect of two endophyte strains associated with $S$. arundinaceus on bird visitations to two fully operational airfields in New Zealand. 


\section{MATERIALS AND METHODS}

A series of small trials were established at Christchurch International Airport Limited (CIAL) in the South Island and Hamilton International Airport in the North Island of New Zealand. The existing vegetation at both airports was composed of an uncultivated mix of plant species typical of that found in low fertility sites in New Zealand. This mix was dominated by grasses, legumes and herbs. The farmland adjacent to CIAL consisted of a grain legume, peas (Pisum sativum), grown for livestock forage. An immunodetection protocol was used to determine the viable endophytic frequency of all grass-endophyte associations utilised in each trial before sowing as described by Card et al. (2014).

\section{Trial 1 at CIAL (October 2007 - October 2008)}

The trial design consisted of six plots (each 0.25 ha) sown at the eastern edge of the east-west runway of CIAL. One plot was designated for S. arundinaceus cv. Jackal AR601, one for cv. Jackal AR604, and the remaining four plots were composed of the existing airport vegetation.

It was not possible to establish a true control plot, such as endophyte-free lines of cv. Jackal, due to the possible increase in bird numbers that could subsequently lead to bird strike. Therefore, comparisons were made with the existing airport vegetation. The two plots for $S$. arundinaceus were cleared of the existing vegetation and then sown by direct drilling at $200 \mathrm{~kg}$ seed/ha in autumn (April) 2007. Using binoculars, from a vehicle situated at a distance of at least $100 \mathrm{~m}$, the resident wildlife officer recorded the number of birds present on each of the plots. In addition, bird species and behaviour (separated into two categories; loafing or grazing), were recorded for each plot. Data were recorded twice daily for a 10 -min period in the morning (0900 hrs) and evening (1700 hrs) for 12 months starting in spring (October) 2007.

\section{Trial 2 at CIAL (March - July 2010)}

In autumn (April) 2009, 16 ha of S. arundinaceus cv. Jackal AR601 was sown on the southern airport threshold area at CIAL. The site was cleared of vegetation and to obtain satisfactory ground cover, seed were cross drilled at $100 \mathrm{~kg} /$ ha to obtain a diamond pattern to a depth of $10 \mathrm{~mm}$. A basal NPK (15-10-10) fertilizer was applied concurrently at $250 \mathrm{~kg} / \mathrm{ha}$. A further two 16 ha areas adjacent to the S. arundinaceus plot, one composed of the existing airport vegetation and the other on neighbouring farmland, were designated control plots. From March to July 2010 the resident wildlife officer observed and recorded bird numbers as described for Trial 1.

\section{Trial 3 at CIAL (July 2011 - January 2012)}

Trial 3 was undertaken on the existing S. arundinaceus plots established for Trial 2. The areas covered were made up of four $250 \mathrm{~m}^{2}$ plots; two of S. arundinaceus cv. Jackal AR601 and two of the existing airport vegetation as mentioned previously. Bird numbers and species data were obtained between June 2011 and January 2012 from the resident wildlife officer as described for Trial 1 with the exception that the officer was aided by a vehicle-installed computer and software package (Ultima ${ }^{\odot}$ V3, Scarecrow Bioacoustic Systems Ltd., Maresfield, U.K.) that can be used for bird dispersal, logging and analysis (continuous monitoring between dawn and dusk). The package has built-in GPS technology and is therefore able to obtain data on bird positioning within the plots.

\section{Trial 4 at Hamilton Airport (September 2010 - May 2012)}

Two 1-ha plots, one kilometre apart, of S. arundinaceus cv. Jackal AR601 were sown at Hamilton airport in March 2010 following an appraisal of the airport's bird-strike hazard management action plan. The existing vegetation was cleared before sowing S. arundinaceus cv. Jackal AR601 by direct drilling in two diagonal passes of $100 \mathrm{~kg} / \mathrm{ha}$ each to deliver at a total rate of $200 \mathrm{~kg} / \mathrm{ha}$ and single super phosphate $(9 \mathrm{P}, 11$ S) and $20 \mathrm{Ca}(300 \mathrm{~kg} / \mathrm{ha})$ was also applied. From September 2010 to May 2012 bird numbers were observed and recorded, together with bird species and behaviour, on the plots once a month for a 10 -min period for each plot from $0800 \mathrm{~h}$, as described for Trial 1. 


\section{Trial 5 - Post establishment of S. arundinaceus cv. Jackal AR601 at CIAL}

A further sowing of $S$. arundinaceus cv. Jackal AR601 was undertaken in March 2013 at the northern end of CIAL following the same procedures as Trial 2. Two 25-ha grass plots at the northern and southern end (those established for Trial 2) of CIAL were monitored for bird numbers pre- and post-establishment of S. arundinaceus cv. Jackal AR601 using the Ultima 3 equipment as for Trial 3. Bird numbers prior to the establishment of S. arundinaceus cv. Jackal AR601 were recorded from 1 August 2011 until 31 July 2012 while bird numbers after the establishment of S. arundinaceus cv. Jackal AR601 were recorded from 31 July 2013 to 31 July 2014.

\section{Bird-strike data}

Data concerning the number of bird strikes to aircraft between 2000 and 2014, at CIAL and Hamilton airports, was supplied by the Civil Aviation Authority of New Zealand (CAA). The CAA collects bird-incident rates quarterly by airfield. This figure is then divided by the number of aircraft movements at each airfield for the same quarter and multiplied by 1,000 to achieve strikes per 1,000 aircraft movements. Aircraft movements at airfields were obtained from Airways New Zealand (Airways Corporation of New Zealand Limited) and, where available, from individual airport companies.

\section{Statistical analysis}

Monthly bird numbers in Trials 1, 2, 3 and 4 - Monthly bird numbers (total of the numbers of all bird species observed daily in each month, including both loafing and grazing) were combined into a single data set, and analysed by a generalised estimating equations (GEE) method. Analysing the combined data improved estimate of the treatment effect, which were consistent across these trials. The GEE analysis used group-specific negative binomial distributions through a loglink function to model the distributions of bird counts. The groups were defined by combination of three factors: (i) treatment - two levels, either S. arundinaceus (cv. Jackal AR601 or AR604) or control (existing airport vegetation plots); (ii) month - 12 levels from January to December; and (iii) airport - two levels, Christchurch or Hamilton. A linear statistical model was used that consisted of these three factors and their full-factorial interactions. In order to offset plot/ area size differences between the trials, the linear model also included plot/area size as an additional covariate. In the GEE analysis, any correlation between the bird counts repeatedly measured from same plots at each airport, and time (averaged monthly over each trial period), was modelled by the first-order autoregressive covariance structure.

Post-trial establishment of S. arundinaceus $c v$. Jackal AR601 in Trial 5 - Total bird counts from the periods of pre- and post-establishment of S. arundinaceus cv. Jackal AR601 were compared in another GEE analysis, separately for data collected at the northern and southern end of CIAL. In this analysis, correlation between the monthly bird counts was modelled also by the first-order autoregressive covariance structure, and the distributions of bird counts as negative binomial distributions. However, the groups being compared were the two time periods - i.e. pre-establishment period vs. postestablishment period.

Bird numbers by species in Trial 2 - Total counts of each bird species (total of both loafing and grazing) and grazing counts (numbers of each species that were grazing) were analysed separately. Each analysis used an identical zeroinflated generalised linear modelling (GLM) approach, which consisted of two GLMs: the first GLM assuming binomial distributions through logit link function, and the second GLM assuming negative binomial distributions through log link function. Each GLM took account of the effects of treatments (existing airport vegetation, farmland and S. arundinaceus cv. Jackal AR601 plots) only. Comparisons between months were not made since each bird species was observed only a small number of times during Trial 2. The zero-inflated modelling approach took account of large numbers of days when no birds were observed i.e. large numbers of zero counts in the data, with the binomial GLM comparing probability of 
observing at least one bird on any day between the three treatments, then, the negative binomial GLM comparing observed non-zero bird counts between the treatments.

Bird strike numbers - Bird strike numbers were analysed using a LOESS (local regression) method to detect a change point (year when an upward trend changed into a downward trend) at each airport. This was followed by linear spline analysis, which fitted two regression lines joined at the change point (one for upward trend and the other for downward trend) to test whether the upward trend was statistically significantly different from the downward trend. All statistical analyses were carried out with SAS version 9.3. (PROC GENMOD for all GEE analyses and PROC GLM for the bird strike number analysis) except for the zero-inflated GLM analyses, which used ZEROINFL function in statistical software $\mathrm{R}$ version 2.8.1.

\section{RESULTS}

\section{Trials 1, 2 and 3 at CIAL}

Viable endophyte-infection frequencies were greater than $96 \%$ for Trials 1 and 2 and greater than $70 \%$ for Trial 3 at CIAL. The number of birds observed on $S$. arundinaceus cv. Jackal AR601 plots compared with plots consisting of the existing airport vegetation at CIAL was lower $(\mathrm{P} \leq 0.05)$ for the months of March, June, July, October and November. In March, for example, fewer $(\mathrm{P}<0.001)$ birds (four on average) were observed on the $S$. arundinaceus $\mathrm{cv}$. Jackal AR601 plots compared with plots consisting of the existing airport vegetation (57 birds on average) and for October, fewer $(\mathrm{P}<0.005)$ birds were observed on the $S$. arundinaceus $\mathrm{cv}$. Jackal AR601 plots (45 on average) compared with the existing vegetation plots (128 birds on average) (Figure 1). Although non-significant at the 5\% level, a similar trend was also observed for the remaining 7 months of the year (Figure 1). In September, for example, bird counts recorded were above 350 per $250 \mathrm{~m}^{2}$ for the S. arundinaceus cv. Jackal AR601 plots and above 470 per $250 \mathrm{~m}^{2}$ for the existing airport vegetation plots (Figure 1). At CIAL, when the bird numbers were averaged over 12 months, the overall mean of 57/plot from S. arundinaceus cv. Jackal AR601 plots was less than a half of the overall mean of 118/plot in the existing airport vegetation (Table 1$)(\mathrm{P}=0.001)$.

\section{Trial 4 at Hamilton Airport}

At Hamilton airport the mean bird count per $250 \mathrm{~m}^{2}$ was lower $(\mathrm{P} \leq 0.05)$ on $S$. arundinaceus cv. Jackal AR601 plots compared with plots consisting of the existing airport vegetation for seven months of the year: February, March, May, June, August, November and December (Figure 2). In February, for example, fewer $(\mathrm{P}<0.001)$ birds were observed on the $S$. arundinaceus $\mathrm{cv}$. Jackal AR601 plots (0.5 birds/plot on average) compared with the plots consisting of the existing

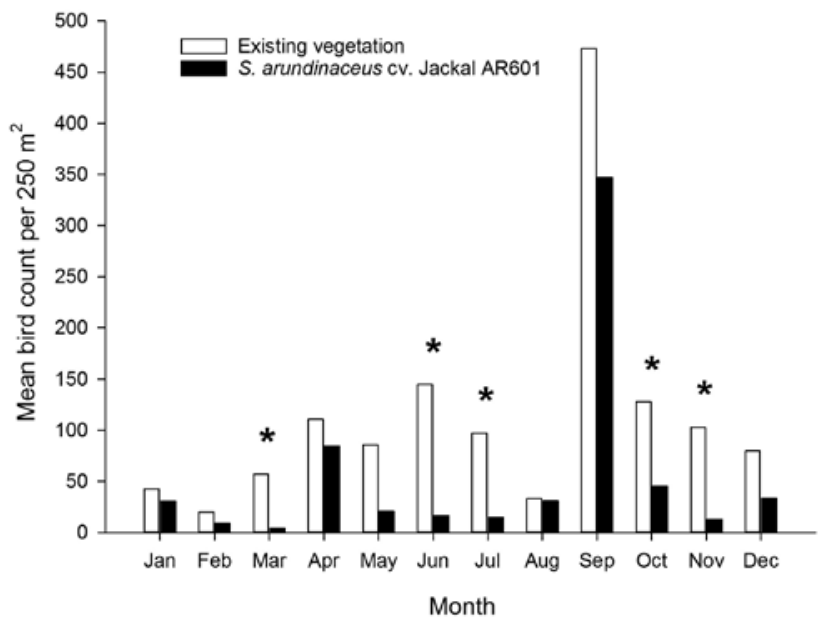

Figure 1 Mean bird counts over a 12 month period from CIAL, from combined data from CIAL Trials 1, 2 and 3 forming a single data set, and analysed by generalized estimating equations (GEE). Trial 1 was conducted between October 2007 and October 2008, Trial 2 between March and July 2010 and Trial 3 between July 2011 and January 2012. ${ }^{\star}$ Bird count significantly $(\mathrm{P} \leq 0.05)$ lower at $S$. arundinaceus cv. Jackal AR601 plots compared to plots consisting of the existing airport vegetation. 
Table 1 Mean observed bird numbers ( \pm SEM) by treatment at CIAL (Trials 1, 2 and 3 combined) and Hamilton airport (Trial 4).

\begin{tabular}{lccc}
\hline & \multicolumn{2}{c}{ Mean observed bird numbers $\left(\right.$ per $\left.250 \mathrm{~m}^{2}\right) \pm$} \\
SEM per plot
\end{tabular}

airport vegetation (43 birds/plot on average) (Figure 2). For the remaining five months of the year, numbers of birds recorded were not statistically different between $S$. arundinaceus $\mathrm{cv}$. Jackal AR601 and the existing airport vegetation plots $(\mathrm{P}>0.05)$. At Hamilton airport when the overall mean bird number across 12 months was compared, the existing airport vegetation plots had more than five times as many birds than the $S$. arundinaceus cv. Jackal AR601 plots (Table 1) $(\mathrm{P}=0.011)$.

\section{Trial 5 - Post establishment of $S$. arundinaceus cv. Jackal AR601 at CIAL}

The difference between pre- and post$S$. arundinaceus $\mathrm{cv}$. Jackal AR601 for the northern end of CIAL was not significant $(\mathrm{P}=0.129)$, although a trend was observed (Figure $3 \mathrm{~A}$ ) that fewer birds observed every month on the northern region of the airport after the establishment of $S$. arundinaceus cv. Jackal AR601. The means between pre- and postS. arundinaceus $\mathrm{cv}$. Jackal AR601 for the southern airport area differed across the year $(\mathrm{P}<0.0001)$. The largest difference was for the months of September and October where 125 and 81 more birds, respectively, where observed before the establishment of S. arundinaceus cv. Jackal AR601 (Figure 3B). The total bird counts observed at CIAL for the months March to July 2010 were 4886, 2750 and 374 for farmland, existing airport vegetation and $S$. arundinaceus cv. Jackal AR601 plots, respectively (Trial 2). The most numerous bird species observed at CIAL were the common starling (Sturnus vulgaris), followed by spurwinged plovers (Vanellus miles novaehollandiae),

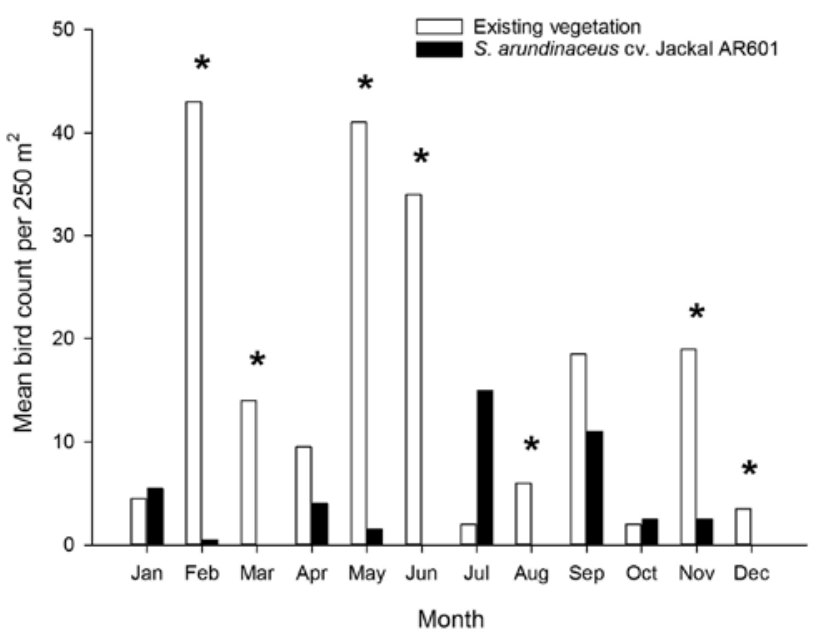

Figure 2 Mean bird counts over a 12 month period at Hamilton Airport, from Trial 4 that was conducted between September 2010 and May 2012. Data analysed by generalized estimating equations (GEE). ${ }^{\star}$ Bird count significantly $(\mathrm{P} \leq 0.05)$ lower on S. arundinaceus cv. Jackal AR601 plots compared to plots consisting of the existing airport vegetation. 
(A) Northern area of CIAL

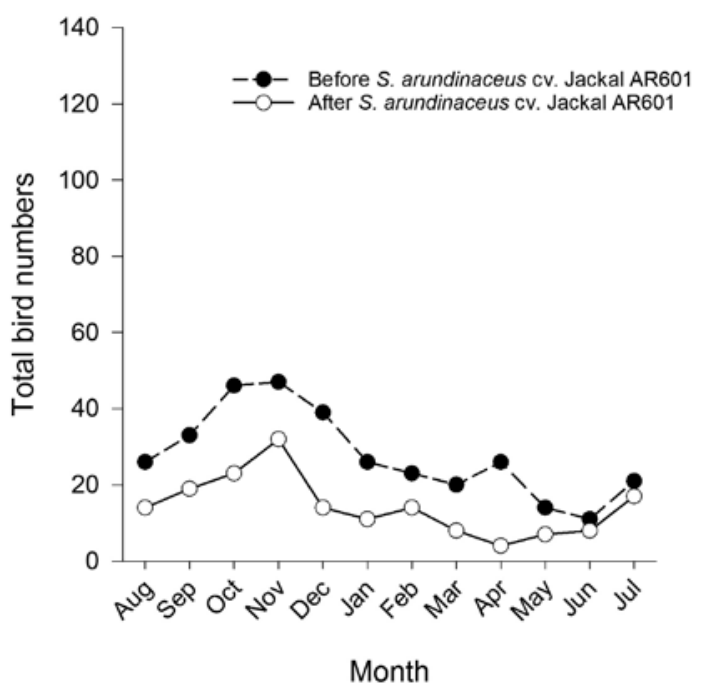

(B) Southern area of CIAL

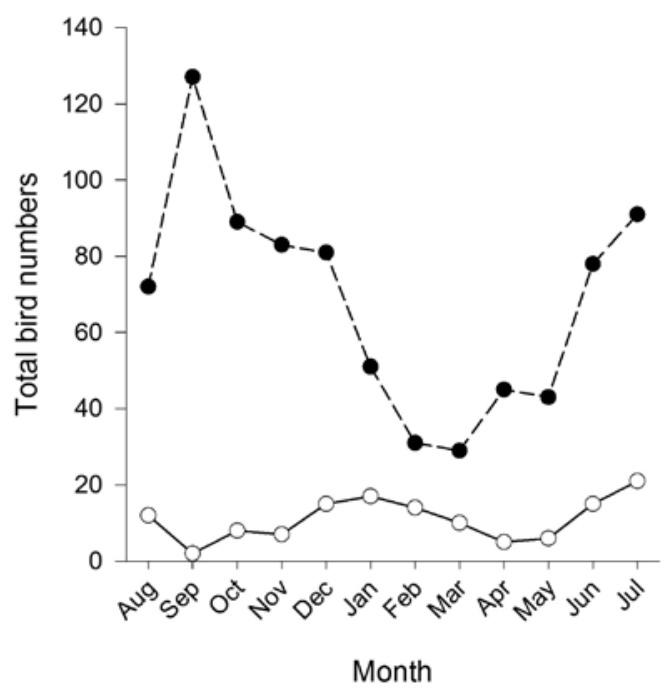

Figure 3 Total bird numbers recorded at the northern and southern areas of CIAL, pre- and postestablishment of $S$. arundinaceus cv. Jackal AR601. Bird numbers prior to the establishment of Jackal AR601 were recorded from 1 August 2011 until 31 July 2012 while bird numbers after the establishment of Jackal AR601were recorded from 31 July 2013 to 31 July 2014.

the European greenfinch (Carduelis chloris) and the Australian magpie (Gymnorhina tibicen). These birds cover the spectrum of omnivorous, insectivorous and granivorous species. Over the 5-month period, very few observations were made of several other bird species, for example only four observations were made of paradise shelducks (Tadorna variegate), loafing on S. arundinaceus cv. Jackal AR601 plots and one observation of a swamp harrier (Circus approximans) loafing on a farmland plot. As numbers were low and neither of these bird species was grazing, this data was excluded from further analysis.

Significantly $(\mathrm{P}<0.05)$ fewer finches, magpies and starlings were observed on $S$. arundinaceus cv. Jackal AR601 plots compared with the existing airport vegetation plots at CIAL for the whole 5-month period from March to July 2010 (Table 2). For plovers, there was no significant difference between the numbers observed on S. arundinaceus cv. Jackal AR601 plots and the existing vegetation, although both these treatments recorded a significantly $(\mathrm{P}<0.05)$ lower number of birds per day than the farmland plots (Table 2). These comparisons were made for the whole 5-month period (i.e. not grouped in each month). These results were similar to those obtained for the mean for individual species observed just grazing on each plot as the vast majority of birds observed were grazing. The only exception was for magpies, where significant differences were only found between the existing airport vegetation plots and the $S$. arundinaceus cv. Jackal AR601 plots (data not shown).

\section{Bird strike data}

The number of bird strikes recorded at CIAL gradually increased from 2000, reaching a peak of 1.83 strikes per 1000 aircraft movements in 2011 (Figure 4). Since 2011, the number of bird strikes at CIAL have started to fall with 1.42 and 1.47 bird strikes per 1000 aircraft movements recorded for 2013 and 2014, respectively (Figure 4). The LOESS analysis detected a change point (year when an upward trend changed into a 
Table 2 Mean total bird count per day ( \pm SEM) of individual bird species observed grazing and loafing on existing airport vegetation, farmland and S. arundinaceus cv. Jackal AR601 plots from March to July 2010 at or near CIAL. For each species, columns followed by the same letter are not significantly different $(\mathrm{P}>0.05)$ according to negative binomial GLM.

Mean bird count per day \pm SEM per plot

\begin{tabular}{lrlrlrr} 
Species & Existing vegetation & \multicolumn{2}{c}{ Farmland } & \multicolumn{2}{c}{$\begin{array}{c}\text { S. arundinaceus cv. } \\
\text { Jackal AR601 }\end{array}$} \\
\hline Finch & $3.4 \pm 0.8$ & A & $0.1 \pm 0.1$ & AB & $0.09 \pm 0.05$ & B \\
Magpie & $1.6 \pm 0.3$ & A & $0.1 \pm 0.1$ & B & $0.03 \pm 0.02$ & B \\
Plover & $0.4 \pm 0.1$ & B & $4.1 \pm 0.9$ & A & $0.9 \pm 0.2$ & B \\
Starling & $12.5 \pm 3.9$ & B & $27.6 \pm 6.8$ & A & $1.4 \pm 0.5$ & C \\
\hline
\end{tabular}

downward trend) at 2011 with 1.7 bird strikes per 1000 aircraft movements, while the linear spline analysis determined the slope of the two regression lines was statistically significantly different $(\mathrm{P}<0.0001)$, providing evidence that the upward trend in the number of bird strikes at CIAL changed after 2011 into the downward trend. The number of bird strikes at Hamilton airport reached a peak of 1.13 strikes per 1000 aircraft movements in 2006 (Figure 5). Since that time, the number of bird strikes decreased with 0.24 and 0.25 bird strikes per 1000 aircraft movements recorded for 2013 and 2014, respectively (Figure 5). These are the lowest values recorded at this airport since 2000 . The LOESS analysis detected a change point halfway through 2005 with 0.87 bird strikes per 1000 aircraft movements while the slope of the two regression lines was statistically significantly different $(\mathrm{P}<0.0004)$, again providing evidence that the upward trend changed after 2005 into the downward trend.

\section{DISCUSSION}

At both CIAL and Hamilton airports, there were significantly fewer birds observed on $S$. arundinaceus cv. Jackal AR601 plots compared with plots composed of the original uncultivated ground cover for many months of the year across many years of trials. For CIAL, this corresponds with data collected by the CAA on the number of bird strikes experienced by the airport before

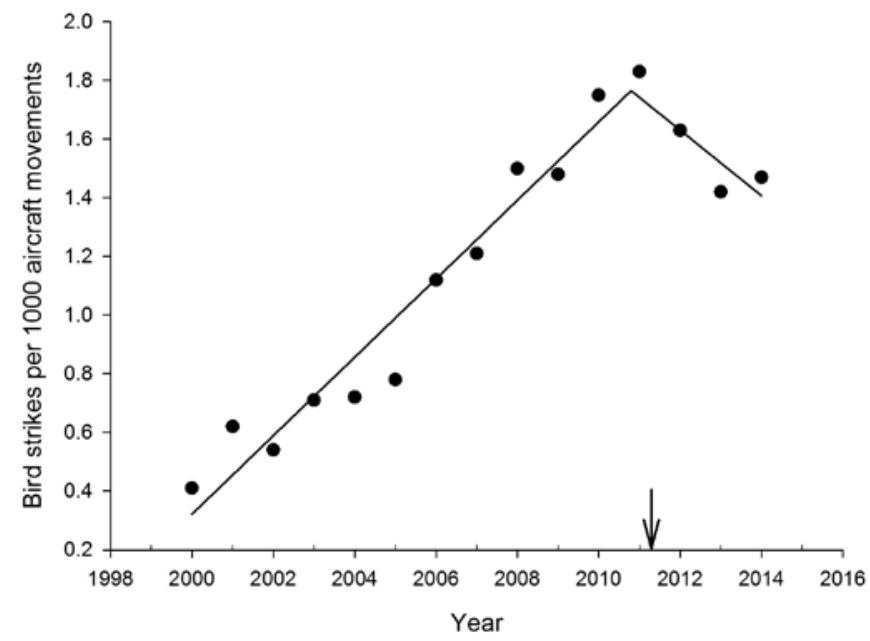

Figure 4 The number of bird strikes recorded at CIAL, per 1000 aircraft movements from 2000 to 2014. The fitted line from the linear spline analysis indicates two straight regression lines joined at the change point detected by LOESS analysis. Arrow indicates the date S. arundinaceus cv. Jackal AR601 was first established at CIAL. 


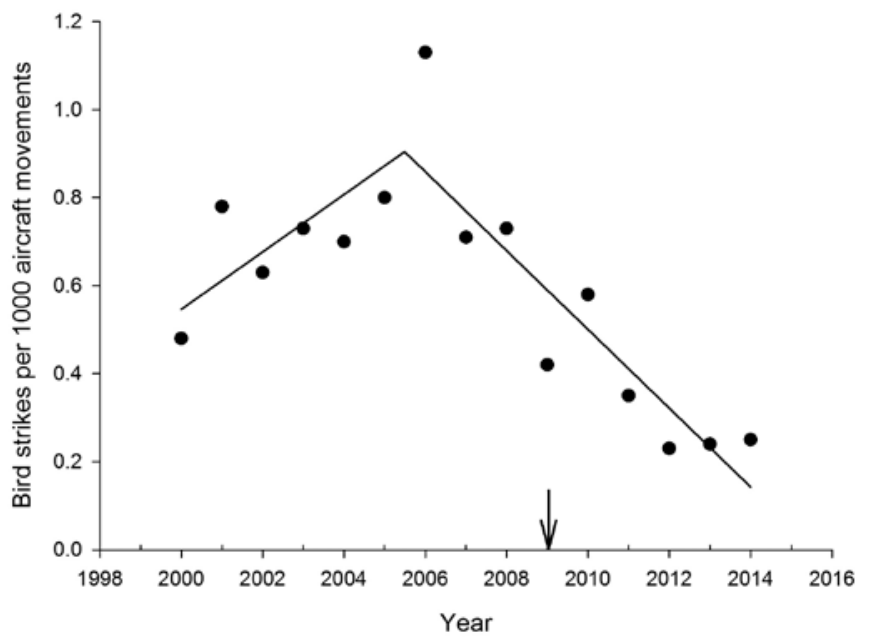

Figure 5 The number of bird strikes recorded at Hamilton airport, per 1000 aircraft movements from 2000 to 2014. The fitted line from linear spline analysis indicates two straight regression lines joined at the change point detected by LOESS analysis. Arrow indicates the date S. arundinaceus cv. Jackal AR601 was first established at Hamilton airport. and after the introduction and establishment of S. arundinaceus cv. Jackal AR601. At Hamilton airport, S. arundinaceus cv. Jackal AR601 performed better or similar to plots composed of the original uncultivated ground cover for the majority of the year except during July. Starlings were the dominant observed species during this month. Cultivar AR601 showed small advantages over AR604 over some experiments (Pennell et al. 2010) and, therefore, subsequent trials within this study and elsewhere (Finch et al. 2016; Pennell et al. 2016; Pennell et al. 2017) were conducted with only AR601.

In 2011, CIAL showed a dramatic increase in the number of birds on existing airport vegetation and $S$. arundinaceus cv. Jackal AR601 plots for the month of September compared with other months in the year. Observational data revealed that large flocks of seed-eating songbirds belonging to the family Fringillidae (the true finches) dominated this month. These birds, including the European greenfinch, are particularly attracted to flowering annual grasses (e.g. Poa annua) that are common on airfields and are known to congregate in large flocks outside of the breeding season (Higgins et al. 2006). Poa annua is naturalised in New Zealand from Europe and seeds prolifically throughout the year (Thomas \& Davies 1964). On inspection, this grass was observed in the establishing S. arundinaceus $\mathrm{cv}$. Jackal AR601 grass plots as an invasive weed and formed a natural component of the existing airport vegetation.

The relationship between birds and secondary metabolites produced by Epichloé endophytes has been previously documented (Madej \& Clay 1991; Conover \& Messmer 1996a; Conover \& Messmer 1996b; Conover 2003; Pennell \& Rolston 2003). However, S. arundinaceus cv. Jackal AR601 is the first grass-endophyte association specifically developed and patented as an aviandeterrent (Publication Number: US2008299144, WO2008133533, UY31054). The mechanism responsible for bird deterrence is believed to be twofold: 1) direct activity through the production of the alkaloid ergovaline that triggers postdigestion feedback where mild illness in birds alters their long-term food preference; and 2) indirect deterrence through the production of loline alkaloids that reduce invertebrate numbers (Pennell et al. 2016), a food source of many birds.

Particularly suited for airfields in temperate climatic zones, S. arundinaceus cv. Jackal AR601 (developed into the product known as Avanex) reduces the attractiveness of airfields to many bird species, and is, therefore, classified as a habitat modifier. This strategy is seen as the most effective long-term solution to reducing many wildlife problems and is recognised internationally as one of the most efficient and humane ways to reduce bird numbers (Blackwell et al. 2009; DeVault et al. 2011). 


\section{ACKNOWLEDGEMENTS}

S. Monk of Grasslanz Technology Limited (GTL) managed the nucleus and breeders seed multiplications. N. Mannix and D. Bennet of CIAL made the bird observations. Airport bird strike data was supplied by K. Stove of the Civil Aviation Authority (CAA) of New Zealand. CIAL Airport fire service staff for supporting research staff visits. D. Ryan of AgResearch Limited for bird observations at Hamilton Airport. Additional statistical support was provided by C.M. McKenzie and L. Hall, AgResearch Limited and D. B. Baird, VSN (NZ) Limited. Funding was provided by CIAL, the Foundation for Arable Research, GTL and PGG Wrightson Seeds Limited. Avanex ${ }^{\circledR}$ is a registered trademark of PGG Wrightson Seeds Limited.

\section{REFERENCES}

Allan JR 2002. The costs of bird strikes and bird strike prevention. Human conflicts with wildlife: Economic considerations In: USDA National Wildlife Research Center Symposia, Lincoln, USA, Pp. 147-153

Baxter AT, Allan JR 2008. Use of lethal control to reduce habituation to blank rounds by scavenging birds. The Journal of Wildlife Management 72: 1653-1657.

Blackwell BF, Fernandez-Juricic E 2013. Behavior and physiology in the development and application of visual deterrents at airports. In: DeVault TL, Blackwell BF, Belant JL eds. Wildlife in airport environments: preventing animal-aircraft collisions through science based management. Johns Hopkins University Press, Baltimore, USA. Pp. 11-22.

Blackwell BF, DeVault TL, Fernández-Juricic E, Dolbeer RA 2009. Wildlife collisions with aircraft: A missing component of land-use planning for airports. Landscape and Urban Planning 93: 1-9.

Card SD, Rolston MP, Lloyd-West C, Hume DE 2014. Novel perennial ryegrassNeotyphodium endophyte associations: relationships between seed weight, seedling vigour and endophyte presence. Symbiosis 62: 51-62.
Cleary EC, Dolbeer RA 2005. Wildlife hazard management at airports: a manual for airport personnel. USDA National Wildlife Research Center - Staff Publications. U.S. Department of Transportation, Federal Aviation Administration, Office of Airport Safety and Standards. Paper 133.

Cleary EC, Wright SE, Dolbeer RA 2005. Wildlife strikes to civil aircraft in the United States 1991-2004. U.S. Department of Transportation, Federal Aviation Administration Series. Report number 11.

Coley AB, Fribourg HA, Pelton MR, Gwinn KD 1995. Effects of tall fescue endophyte infestation on relative abundance of small mammals. Journal of Environmental Quality 24: 472-475.

Conover MR 2003. Impact of consuming tall fescue seeds infected with the endophytic fungus, Neotyphodium coenophialum, on reproduction of chickens. Theriogenology 59: 1313-1323.

Conover MR, Messmer TA 1996a. Feeding preferences and changes in mass of Canada geese grazing endophyte-infected tall fescue. Condor 98: 859-862.

Conover MR, Messmer TA 1996b. Consequences for captive Zebra finches of consuming tall fescue seeds infected with the endophytic fungus Acremonium coenophialum. The Auk 113: 492-495.

DeVault TL, Belant JL, Blackwell BF, Seamans TW 2011. Interspecific variation in wildlife hazards to aircraft: Implications for airport wildlife management. Wildlife Society Bulletin 35: 394-402.

DeVault TL, Begier MJ, Belant JL, Blackwell BF, Dolbeer RA, Martin JA, Seamans TW, Washburn BE 2013. Rethinking airport land-cover paradigms: agriculture, grass, and wildlife hazards. Human-Wildlife Interactions 7: 10-15.

Dolbeer RA, Wright SE, Weller J, Begier MJ 2011. Wildlife strikes to civil aircraft in the United States, 1990-2009. National Wildlife Strike Database Serial Report No. 16. Federal Aviation Administration Office of Airport Safety and Standards. 
Durham WF, Tannenbaum MG 1998. Effects of endophyte consumption on food intake, growth, and reproduction in prairie voles. Canadian Journal of Zoology 76: 960-969.

Federal Aviation Administration 2012. Wildlife hazard assessments and wildlife management plans at part 139 and GA Airports. Washington, USA.

Finch SC, Pennell CGL, Kerby JWF, Cave VM 2016. Mice find endophyte-infected seed of tall fescue unpalatable - implications for the aviation industry. Grass and Forage Science 71: 659-666.

Godin AJ 1994. Birds at airports. In: Hygnstrom SE, Tim RM, Larson GE eds. The Handbook: Prevention and Control of Wildlife Damage University of Nebraska, USA. Section E-1.

Higgins PJ, Peter JM, Cowling SJ 2006. Family Fringillidae Old World finches. Oxford University Press, Melbourne, Australia. Pp. 1302-1305.

Johnson L, de Bonth A, Briggs L, Caradus J, Finch S, Fleetwood D, Fletcher L, Hume D, Johnson R, Popay A, Tapper B, Simpson W, Voisey C, Card S 2013. The exploitation of epichloae endophytes for agricultural benefit. Fungal Diversity 60: 171-188.

Leuchtmann A, Bacon CW, Schardl CL, White JF, Tadych M 2014. Nomenclatural realignment of Neotyphodium species with genus Epichloé. Mycologia 106: 202-215.

Madej CW, Clay K 1991. Avian seed preference and weight loss experiments: the effect of fungal endophyte-infected tall fescue seeds. Oecologia 88: 296-302.

Panaccione D, Cipoletti J, Sedlock A, Blemmings K, Shardl C, Machodo C, Seidel G 2006. Effects of ergot alkaloids on food preference and satiety in rabbits, as assessed with geneknockout endophytes in perennial ryegrass (Lolium perenne). Journal of Agricultural and Food Chemistry 54: 4582-4587.
Pennell C, Rolston M 2003. The effect of grassendophyte associations on feeding of Canada geese (Branta canadensis). In: Proceedings of the New Zealand Grasslands Association, Palmerston North, New Zealand, Pp. 239-243

Pennell C, Rolston M, de Bonth A, Simpson W, Hume D 2010. Development of a birddeterrent fungal endophyte in turf tall fescue. New Zealand Journal of Agricultural Research 53: 145-150.

Pennell C, Rolston M, Latham A, Mace W, Vlaming J, van Koten C, Latham M, Brown S, Card S 2017. Novel grass-endophyte associations reduce the feeding behaviour of invasive European rabbits (Oryctolagus cuniculus). Wildlife Research 43: 681-690.

Pennell CGL, Popay AJ, Ball OJP, Hume DE, Baird DB 2005. Occurrence and impact of pasture mealybug (Balanococcus poae) and root aphid (Aploneura lentisci) on ryegrass (Lolium spp.) with and without infection by Neotyphodium fungal endophytes. New Zealand Journal of Agricultural Research 48: 329-337.

Pennell CGL, Popay AJ, Rolston MP, Townsend RJ, Lloyd-West CM, Card SD 2016. Avanex Unique Endophyte Technology - a biological deterrent for the aviation industries. Environmental Entomology 45: 101-108.

Solman VEF 1981. Birds and aviation. Environmental Conservation 8: 45-51.

Thomas J, Davies L 1964. Common British grasses and legumes. Longmans, London.

Washburn BE, Loven JS, Begier MJ, Sullivan DP, II HAW 2007. Evaluating commercially available tall fescue varieties for airfields. In: FAA worldwide Airport Technology Transfer Conference Atlantic City, New Jersey, USA. 